\title{
nutrients
}

ISSN 2072-6643

www.mdpi.com/journal/nutrients

Review

\section{Diet-Microbiota Interactions and Their Implications for Healthy Living}

\author{
Ian B. Jeffery ${ }^{1,2, *}$ and Paul W. O'Toole ${ }^{1,2}$
}

1 Department of Microbiology, University College Cork, College Road, Cork, Ireland; E-Mail: pwotoole@ucc.ie

2 Alimentary Pharmabiotic Centre, University College Cork, College Road, Cork, Ireland

* Author to whom correspondence should be addressed; E-Mail: i.jeffery@ucc.ie; Tel.: +353-(0)21-490-1306; Fax: +353-(0)21-490-3997.

Received: 7 December 2012; in revised form: 10 January 2013 / Accepted: 10 January 2013 / Published: 17 January 2013

\begin{abstract}
It is well established that diet influences the health of an individual and that a diet rich in plant-based foods has many advantages in relation to the health and well-being of an individual. What has been unclear until recently is the large contribution of the gut microbiota to this effect. As well as providing basic nutritional requirements, the long-term diet of an animal modifies its gut microbiota. In adults, diets that have a high proportion of fruit and vegetables and a low consumption of meat are associated with a highly diverse microbiota and are defined by a greater abundance of Prevotella compared to Bacteroides, while the reverse is associated with a diet that contains a low proportion of plant-based foods. Furthermore, it is becoming increasingly clear that the effect of the microbial ecology of the gut goes beyond the local gut immune system and is implicated in immune-related disorders, such as IBS, diabetes and inflamm-ageing. In this review, we investigate the evidence that a balanced diet leads to a balanced, diverse microbiota with significant consequences for healthy ageing by focusing on conditions of interest.
\end{abstract}

Keywords: microbial; diversity; IBS; ageing; diet; microbiota; microbiome; SCFA; vitamins

\section{Introduction}

The gastrointestinal tract contains a diverse microbial community, which is predominantly bacterial and which is referred to as the gut microbiota. Over the last decade, the microbial composition of the 
gut has been the subject of increasingly intense research, much due to its demonstrated impact upon various health conditions. The Human Microbiome Project (HMP), MetaHIT (Metagenome of Human Intestinal Tract) and the smaller ELDERMET project, as well as numerous labs around the world (Table 1), have taken advantage of new high-throughput technologies to thoroughly characterise the human microbiome from multiple body sites at every stage of life. A number of these projects employed whole-community shotgun sequencing to study the gene content of the microbial populations. Through these studies, it has become apparent that these microorganisms are not just passive residents of the gut, but carry out a range of biological functions that are important in the nutrition and well-being of the individual.

Table 1. Microbiome consortiums.

\begin{tabular}{|c|c|c|c|}
\hline Program & Duration & Funding Organization & Conditions of Interest \\
\hline NIH Jumpstart Program & 2007-2008 & NIH, USA & $\begin{array}{l}\text { Generate } 200 \text { complete bacterial genome sequences and perform compositional } \\
\text { analysis of various body regions. }\end{array}$ \\
\hline $\begin{array}{l}\text { NIH Human } \\
\text { Microbiome Project }\end{array}$ & 2007 & $\begin{array}{l}\text { NIH Roadmap Program, } \\
\text { USA }\end{array}$ & $\begin{array}{l}\text { Characterize the microbes on the human body and correlate the changes in these } \\
\text { microbial populations with human health. }\end{array}$ \\
\hline $\begin{array}{l}\text { DACC_-Data Analysis } \\
\text { and Coordination Center }\end{array}$ & 2008-2013 & $\begin{array}{l}\text { NIH Human Microbiome } \\
\text { Project (HMP), USA }\end{array}$ & $\begin{array}{l}\text { Assist in standardization of data pipelines (storage, analysis and display of data) } \\
\text { and provide access to data. }\end{array}$ \\
\hline $\begin{array}{l}\text { MetaHIT, } \\
\text { Metagenomics of the } \\
\text { Human Intestinal Tract }\end{array}$ & 2008-2011 & $\begin{array}{l}\text { European Commission } \\
\text { (FP7) }\end{array}$ & $\begin{array}{l}\text { Describe the role of the microbiota in Inflammatory Bowel Disease (IBD) and } \\
\text { obesity, and generate a reference catalogue of intestinal microbial genes. }\end{array}$ \\
\hline $\begin{array}{l}\text { Canadian Human } \\
\text { Microbiome Initiative }\end{array}$ & 2009 & $\begin{array}{l}\text { Canadian Institutes of } \\
\text { Health Research (CIHR), } \\
\text { Canada }\end{array}$ & $\begin{array}{l}\text { A number of projects relating to human microbial interactions and their effect } \\
\text { on health. }\end{array}$ \\
\hline $\begin{array}{l}\text { The Australian } \\
\text { Jumpstart Human } \\
\text { Microbiome Project }\end{array}$ & 2009 & $\begin{array}{l}\text { Commonwealth Scientific } \\
\text { and Industrial Research } \\
\text { Organisation (CSIRO), } \\
\text { Australia }\end{array}$ & $\begin{array}{l}\text { Sequencing of specific bacterial strains and the application of metagenomics } \\
\text { techniques to investigate the interaction between intestinal microbes and } \\
\text { their host. }\end{array}$ \\
\hline $\begin{array}{l}\text { MicroObes, Human } \\
\text { Intestinal Microbiome in } \\
\text { Obesity and Nutritional } \\
\text { Transition }\end{array}$ & $2008-2010$ & $\begin{array}{l}\text { French National Agency } \\
\text { for Research (ANR), } \\
\text { France }\end{array}$ & $\begin{array}{l}\text { Identify metagenomic signatures that characterise the relationship between the } \\
\text { intestinal microbiota and the nutritional and metabolic status of the host. }\end{array}$ \\
\hline $\begin{array}{l}\text { Korean Microbiome } \\
\text { Diversity Using Korean } \\
\text { Twin Cohort Project }\end{array}$ & 2010-2015 & $\begin{array}{l}\text { National Research } \\
\text { Foundation of Korea, } \\
\text { Korea }\end{array}$ & $\begin{array}{l}\text { Determine the microbiomes on various epithelial sites of the human body using } \\
\text { Korean Twin Cohort and investigate the relationship between human } \\
\text { microbiomes and disease. To establish a dedicated centre for Korean } \\
\text { microbiome information and analysis. }\end{array}$ \\
\hline ELDERMET Project & 2007-2013 & $\begin{array}{l}\text { National Development } \\
\text { Food Research Health } \\
\text { Initiative and Science } \\
\text { Foundation Ireland }\end{array}$ & $\begin{array}{l}\text { Characterize the faecal microbiota associated with ageing and correlate } \\
\text { diversity, composition, and metabolic potential of the faecal microbial } \\
\text { metagenome with health, diet and lifestyle. }\end{array}$ \\
\hline
\end{tabular}

The most heavily studied part of the gut is the distal colon, through the use of high-throughput next-generation technologies and phylochips to characterise faecal derived populations. In adults, this population is characterised by the predominance of two phyla, Bacteroidetes and Firmicutes, with minor contributions from the Proteobacteria and Actinobacteria [1]. However, it is known that the 
microbial content of the gut changes along its length, with the small intestine containing a higher relative abundance of members of the Actinobacteria and Streptococcaceae [2]. Autochthonous bacteria have evolved within the gut to form a mutually beneficial relationship with their human hosts. Considering the size of the human gut and the density of bacteria that it contains, the nature of this relationship is very relevant. The bacteria in the gut have developed a number of adaptations for living in this unique environment, such as mechanisms for avoiding or modulating inflammatory responses [3]. On the other side of this interaction paradigm, evolution in the host has taken the form of Toll-like receptors (TLR) that are used to identify bacteria (and other antigens) and to respond appropriately as part of an innate and adaptive immune system [4]. The host also produces a complex polymeric barrier or mucin layer that separates the bacteria from the epithelium [5,6]. A number of studies have examined the core human microbiota within the gut, which may be operationally defined as those microbes that are found in a majority of individuals [7]. Qin et al. (2010) [8] found that there are 1000 to 1150 prevalent bacterial species, with each individual harbouring at least 160 species. This translated to 3.3 million non-host-encoded genes of which $99 \%$ were of bacterial origin, with $\sim 536,000$ prevalent unique bacterial genes in each individual of which $40 \%$ would be shared with at least half of the individuals in their cohort. Annotation suggests that these microbial genes are involved in the production of essential metabolites and the degradation and utilisation of complex carbohydrates and biosynthesis of vitamins [8,9].

There are significant inter-individual differences in the presence and absence of the bacterial species found in the gastrointestinal tract. There are a number of highly abundant species that are present in the majority of a population, but the overall composition of the gut depends on the age, health, diet and even geographical location of the individual [10]. These bacteria have a substantial scope to modify the phenotype of the individual though production of metabolites and through interaction with the physiology of the individual in a diverse number of ways. Thus, dietary modulation of the gut microbiota composition and function will have implications for the host phenotype.

\section{Microbiota and Diet}

A number of studies have examined the relationship between the faecal microbiota and diet. De Filippo et al. (2011) [11] showed that the faecal microbiota in a cohort of Italian children was different to that found in children in a rural village in Burkina Faso. Similar to the different microbial populations reported by the ELDERMET consortium [12], Italian children, who consume less plant-based foods, harboured more Bacteroides and Alistipes in their microbiota. The microbiota of the rural Burkina Faso children had an abundance of bacteria from the genus Prevotella, similar to the healthier diet individuals in the ELDERMET cohort. The Burkina Faso children also harboured significantly higher levels of faecal short-chain fatty acid producers than the Italian children. Interestingly Xylanibacter, which was absent in the ELDERMET and Italian microbiota communities, but was present in the Burkina Faso children, is known to contain a set of genes for cellulose and xylan hydrolysis. The main fibres that reach the distal colon and are utilized by the gut microbiota and their enzymes are carbohydrates and proteins that are refractory to host digestion. The level of metabolic activity in the microbiota will depend on how much of these materials are making it down into the gut. Although the microbiota will respond to short-term changes in the diet, the long-term 
changes seem to define what type of microbial population is present and this in turn determines the metabolites produced and the potential impact on the health of the host [13].

Filippo et al. (2011) [11] hypothesized that the gut microbiota co-evolved with the polysaccharide-rich diet of Burkina Faso individuals, allowing them to maximize energy intake from dietary fibre, while also dampening inflammation and protecting them from non-infectious colonic diseases. Wu et al. (2011) [13] also found that the microbiota composition was strongly associated with long-term diet, with Bacteroides being associated with diets enriched in animal products. The Prevotella genus was associated with diets that contained more plant-based foods. All three studies (older persons_-ELDERMET [12]; Burkina Faso versus Italian children [11]; and American adults [13]) found similar microbiota-diet associations at three different stages of life, showing that the diet modulates the microbiota regardless of gender or other confounding factors.

A study performed in the mouse model also showed that switching from a low-fat, plant polysaccharide diet to a high fat, high sugar, Western-style diet lead to alterations in the microbiome and its metabolic function [14]. The high plant polysaccharide diets are full of resistant starch and oligosaccharides that the microbiota can utilise [15] and have been shown to affect the abundances of a number of microbes [16]. Subjects fed resistant starch type 2 from high amylose maize showed an increased abundance of Ruminococcus spp. and Eubacterium rectale, while consumption of resistant starch type 3 (water-insoluble semi-crystalline structures formed from amylose) promoted the growth of Eubacterium rectale, Roseburia spp. and Ruminococcus bromii. These species are able to bind directly to insoluble starch particles and to degrade them and may be the key species in bacterial food chains that target starch [17]. A detailed description on the mechanisms involved in the breakdown of fibre is beyond the scope of this review, but has been recently described [15].

\section{Age-Related Gut Microbiota Changes}

The microbiota composition is not stable over the whole life-time of an individual. At the extremities of life, a number of discernible patterns of microbiota change have been recorded. Since the microbiota and its metabolic activities react and change according to diet, some of these age-related microbiota composition changes may be attributable to diet. The diet in elderly individuals can change for a number of reasons, including loss of sensation of taste and smell, tooth loss and chewing difficulties. These changes may result in an increased consumption of high sugar/high fat foods and a reduction in the proportion of plant-based foods consumed. Although diet-related microbiota changes undoubtedly occur at all life stages, the majority of the research performed to date has been focused on healthy or diseased adults, with fewer investigations having been carried out on children and the elderly. However, in the younger and older subjects in the population, the observed microbial changes can be more dramatic, and so these are an excellent source of information on associations between health and the microbiota. This is particularly true for the study of the development and decline of microbial populations. How these populations change depends on how they are modulated. A recent study by the ELDERMET consortium has focused on elderly individuals, whose dietary patterns were found to change for a number of reasons, one of the most dramatic being the change in diet going into long-term residential care [12]. Within and between the community living subjects and those in long-term care, we uncovered an association between an increase in the 
microbiota diversity in the gut and a diet rich in "healthy foods", as defined by the Healthy Food Diversity index (HFD [18]). Conversely, diets with a low HFD score were associated with microbiota populations that were less diverse and had predicted reduced functionality and so potentially conferring fewer benefits to the respective individual. As well as a difference in diversity levels, there were differences in the dominant genera present in the different subject groups. The microbiota associated with diets rich in plant-based foods were abundant in Prevotella, while the individuals with a lower HFD harboured more Bacteroides. A further reduction in the HFD scores associated with individuals living in long-term care resulted in Parabacteroides and Alistipes becoming the dominant Bacteroidetes genera. These microbiota alterations were associated with changes in frailty, inflammation and altered abundances of short chain fatty acids (SCFAs) producers, as well as correlations with other clinical markers [12].

Intestinal microbiota composition may also vary in elderly subjects independently of diet for a number of physiological and immunological factors, such as a reduction in the immune system functionality [19-21]. This is indicated in the reduced abundance of Ruminococcus and Blautia spp. and the increased abundance of Escherichia in the elderly when compared to young controls [12]. It has been previously reported that the microbiota associated with elderly individuals has a reduced abundance of several butyrate producers (Key members of Clostridium cluster XIVa and Clostridium cluster IV) when compared to younger individuals [22,23]. This was confirmed in the ELDERMET study, where it was shown that the oldest and frailest individuals had significantly lower copy numbers of genes related to butyrate, acetate and propionate production in the faecal metagenome [12]. The age-related increase in the proportion of facultative anaerobes, including Escherichia amongst other genera, has also been noted in previous studies. These bacteria are present at low levels in healthy young adults, but are present in increased abundances in the inflamed gut [22,24,25].

\section{Dietary Modulation}

As global life expectancy increases, it is important to maintain quality of life and independence in the elderly. The study of older persons is starting to provide a wealth of information and more complete understanding of their diet-microbiota interactions. This provides the possibility of modulating the microbiota to benefit health. The mechanisms of dietary modulation of the microbiota include the physical ability of high fibre diets to increase faecal bulk, which is one of the factors that affects transit time along the gut. Jumpertz et al. (2011) [26] have shown that the human gut microbiota can undergo long-term changes that occur over a couple of days when there is a significant increase in the calorie intake of the individual. Transit time itself affects the composition of the human faecal microbiota because, as the transit time decreases, there is a decrease in the proportions of slow growing species, such as methanogens, and an increase in sulphate reducing bacteria counts, while concentrations of total SCFAs are increased, leading to a lowering of faecal $\mathrm{pH}$ [27]. But, more importantly, the macronutrient composition of the ingested food determines which species flourish and which taxa will be able to colonise the gut and, so, determines the eventual composition of the microbiota.

For new taxa to become established and abundant in a stable gut ecosystem, their functionality must permit them to thrive in the presence of other organisms that are competing for resources. At the most basic level, this functionality is conferred by the presence and absence of genes. Autochthonous 
bacteria have coevolved with the human host and each other to perform important roles in nutrient and energy extraction and energy regulation that the host would otherwise be unable to accomplish. There are numerous positive interspecies associations in the gut $[12,28]$, probably due to adaptation to similar substrate-availability and flow-rate environments and to cross-feeding between different organisms [29]. The importance of cross-feeding between different organisms was demonstrated by Samuel and Gordon [30] when they investigated the utilization of polysaccharides by Bacteroides thetaiotaomicron in germ-free mice colonized in the presence and absence of Methanobrevibacter smithii or the sulphate-reducing bacterium Desulfovibrio piger. They found that $M$. smithii directs $B$. thetaiotaomicron to focus on fermentation of dietary fructans to acetate, whereas $B$. thetaiotaomicron-derived formate is used by M. smithii for methanogenesis. B. thetaiotaomicron-M. smithii co-colonization resulted in increased weight gain and energy harvest when compared to mice colonised by $B$. thetaiotaomicron alone or by $B$. thetaiotaomicron and D. piger. Indeed, this type of crossfeeding is an important and widespread phenomenon [12,28,31]. This suggests that targeted dietary modulation of species will affect populations of microbes within the microbiota and, so, modulate energy harvest, storage and expenditure. The microbiota also affects energy balance through metabolites that its members produce. The produced metabolic outputs from the community will depend on what species/genes are present and expressed and what substrates are available to the microbiota [32].

\section{Production of Metabolites}

The gut microbiota performs many functions in the breakdown of complex carbohydrates and the generation of beneficial metabolites. This is made possible by the large array of genes that encode enzymes that are essential to these processes. Germ-free animals that do not contain a microbiota/microbiome still survive and reproduce, but their diet must contain a higher quantity and diversity of essential nutrients to maintain their health [33].

In conventional mice and normal humans, resistant starch and oligosaccharides that are undigested in the small intestine may be utilised in the large intestine by bacteria to produce SCFAs. There are a number of SCFAs that are produced; the most abundant being acetate, propionate and butyrate [34]. These are taken up by the host and may provide up to $10 \%$ of its energy requirements. Butyrate is absorbed by colonocytes and other cells of the colonic epithelium [35], thus providing energy to the host from dietary components that would otherwise pass undigested through the gut. In fact, if colonocytes are deprived of butyrate, they undergo autophagy [36]. Acetate and propionate are taken up by the circulatory system and, so, are utilized by the general physiology, i.e., not just the intestine. Acetate is oxidized in the citric acid cycle [37], and propionate is incorporated into glucose metabolism. As well as being absorbed by the host, SCFAs have been shown to affect transit time through modulation of gut motility [38,39] and to affect insulin sensitivity and energy expenditure, giving them a link to metabolic syndrome [40].

High amounts of SCFAs may decrease the intestinal $\mathrm{pH}$ [41] and prevent the growth of potentially pathogenic bacteria, such as E. coli and other members of the Enterobacteriaceae [42]. While a number of gut bacteria are tolerant of lower $\mathrm{pH}$ values, such as a number of the Firmicutes species, especially those belonging to Clostridium cluster XIVa [43], this low pH tolerance is not a feature of many Bacteroidetes spp. and Bifidobacterium spp. [43], thus making SCFA production a potential 
modulator of these taxa. The increased concentration of SCFAs may also help in the absorption of minerals, such as calcium, by increasing their solubility and increasing the expression of calcium binding proteins [44]. Butyrate also exerts an anti-inflammatory [45] and anti-carcinogenic effect [46] in these cells. SCFAs may also be involved in the control of appetite, as they can be detected by receptors expressed in the gut called free fatty acid receptor 2 (FFAR2) and free fatty acid receptor 3 (FFAR3) [47]. These, in turn, regulate hormones involved in appetite control; thus, the microbiota and its production of SCFAs may have a role to play in food intake of an individual [47].

The microbiota is involved in the production and absorption of essential vitamins and micronutrients. It has been established that the levels of essential vitamins, such as folate and biotin, may be higher in individuals than their diet would suggest/support. This can be attributed to microbial production of folate and biotin, as well as a number of vitamins, including other water soluble B vitamins and vitamin $\mathrm{K}$ [48]. It was assumed that, as these vitamins were produced in the colon, they would not be absorbed, but excreted. This notion was challenged with the discovery of colonic transporters for biotin [49], thiamine [50], riboflavin [51], pyridoxine [52] and folate [53].

Folate is important in synthesis, repair and methylation of DNA and is necessary for cell division and growth. The primary mechanism for dietary folate absorption is its deconjugation to monoglutamates and subsequent absorption by active transport carriers in the small intestine, but evidence suggests that a similar mucosal transport mechanism operates in the colon [53]. Many microorganisms in the large intestine are capable of synthesizing folate. Furthermore, it has been shown that the infant colon contains pools of readily absorbed monoglutamylated folate [54]. A number of studies have indicated that resistant carbohydrate is utilized by the bacteria in the colon in the biosynthesis of folate, particularly Bifidobacterium bifidum and Bifidobacterium longum subsp. infantis [55-57]. A number of other B-group vitamins that are synthesised by members of the microbiota and that may be produced in the gut include riboflavin, vitamin B12, niacin and pyridoxine [58].

Vitamin $\mathrm{K}$ is a group of structurally similar, fat-soluble compounds that are important co-factors in the post-translational modification of certain proteins required for blood coagulation and in metabolic pathways. Microbial conversion of the plant derived vitamin K1 (phylloquinone) to vitamin K2 (menaquinone) is believed to be facilitated by a number of species in the human gut [59-61].

\section{Diet, Microbiota and Functional Bowel Disorders}

There is growing interest in the concept of dietary modulation of the microbiota for improving health. In modern society, disorders with plausible links to microbiota alterations are increasing, such as Irritable Bowel Syndrome (IBS) and obesity [14,62-64]. Irritable Bowel Syndrome (IBS) is the most common of the functional bowel disorders and affects a significant percentage of the population of the industrial world [65]. Although originally thought to be a psychosomatic disorder, it is now regarded as multi-factorial, with genetic, neurological and psychosocial elements, all potentially contributing to symptomology [66]. It is becoming increasingly recognised that low-grade inflammation $[67,68]$ and changes in the gut microbiota are present in a majority of patients, reinforced by observations that probiotic and antibiotic intervention may be effective in reducing the severity of the IBS symptoms $[69,70]$. A microbiota re-configuration associated with the majority of IBS-related 
microbiotas has been confirmed by several studies using high throughput technologies to determine the alterations of the microbiota of the distal bowel in IBS compared to healthy subjects $[63,71-73]$.

Dietary modulation of the microbiota in IBS and functional bloating is of particular interest due to the reported decrease in symptoms associated with the use of the Low FODMAP diet in the treatment of IBS [74]. FODMAP is an acronym derived from "Fermentable, Oligo-, Di-, Mono-saccharides and Polyols" [75]. This diet focuses on reducing the consumption of rapidly fermentable, short-chain carbohydrates that are poorly absorbed in the small intestine, namely fructose (monosaccharide), lactose (disaccharide), fructans and galactans (oligosaccharides) and polyols, such as sorbitol, maltitol, xylitol and mannitol [76]. Poor absorption occurs for a number of reasons; (a) fructose is only slowly absorbed due to low-capacity transport mechanisms across the epithelium [77]; (b) there is a lack of hydrolases of fructans and galactans; and (c) there are no specific transporters for polyols and these molecules are too large for uptake by passive diffusion. For lactose, a proportion of the population is unable to hydrolase the molecule, but this proportion depends on ethnicity [78].

The FODMAPs diet removes these rapidly fermentable substrates altogether or uses breath tests to stratify individuals based on their absorption of fructose and lactose [79]. Interestingly, this test has been also used to detect small intestinal bacterial overgrowth (SIBO; [80]), the eradication of which has been shown to alleviate the symptoms of IBS [65]. There is limited data to suggest that fructose malabsorption and SIBO might have a bidirectional cause-effect relationship, but nevertheless, upon the administration of fructose, there is an increase in the hydrogen produced as measured by the breath test and an increase in the concentration of acetate found in the blood [76], which may be produced by E. coli [81]. It has been shown that a diet that contains no substrates for bacteria to ferment alleviates IBS symptoms in $85 \%$ of cases, accompanied by a normalisation of the lactulose breath test, an indicator of SIBO [82].

At the time of writing, there is no information on how consumption of a FODMAPs diet would affect the microbiota signature detected in faecal samples of IBS subjects. It has been shown that when individuals are fed a high FODMAP diet, a significant proportion of the substrates will pass through the small intestine to the proximal colon [83]. This increased substrate in the proximal colon may explain the reported increased microbial production of SCFAs by the microbiota of IBS subjects [84-86]. Many of the faecal microbiota taxa that have been shown to be associated with IBS, such as Ruminococcaceae and Clostridium cluster XIVa, are known to be enriched for species that produce SCFAs [87]. As described previously, SCFAs are essential to the normal functioning of the gut, but there is some evidence that abnormally high levels of butyrate can promote visceral hypersensitivity [88] and high levels of SCFAs can cause powerful contractions in the terminal ileum [89]. These observations are of clinical relevance, given the association of IBS with visceral hypersensitivity and dysmotility.

The FODMAPs diet alleviates the symptoms of IBS better than other healthy eating advice, with the majority of individuals on the diet reporting improved symptoms [90]. It has not been shown that the diet normalises the individual, and we may speculate that a resumption of the normal diet will result in a resumption of the original symptoms. However, the FODMAPs diet has been shown to be an effective way to alleviate symptoms of functional gastrointestinal disorders.

With regard to food related issues that may have a causative effect, there is a perception among IBS sufferers that they may suffer from food intolerance or allergy, and this leads many IBS subjects to 
initiate a variety of dietary changes [91]. Altering of diets in this regard is common, with $20 \%-70 \%$ of IBS sufferers self-reporting one or more food intolerances [92]. Despite this, clinically validated food hypersensitivity appears to be relatively uncommon in IBS [93], but, when detected, the removal of the offending foods has been associated with a reduction or a complete elimination of symptoms [94,95]. However, the mechanism of action of the FODMAPs diet may explain why IBS symptoms may be eased by a gluten free diet [96], because this diet is low in content of cereals that contain high levels of FODMAP substrates.

\section{Obesity and Metabolic Disorder}

Although the development of obesity and insulin resistance is complex, with many genetic and environmental factors involved [97-103], it is associated with the presence of chronic inflammation in visceral adipose tissue, which is believed to be a leading promoter of insulin resistance in obesity. Studies, primarily in animals, have demonstrated that a number of microbial factors may be associated with the development of metabolic disorder and diabetes [104]. Cani et al. (2008) [105] showed that genetically obese ob/ob mice, which are characterised by obesity and insulin resistance, showed an improvement in insulin sensitivity and inflammatory parameters when treated with antibiotics.

Turnbaugh et al. (2009) [106] reported that obesity is associated with microbial compositional changes at the phylum level. They found that individuals with high BMIs had a lower proportion of Bacteroidetes and a higher proportion of Actinobacteria when compared to leaner individuals. This agreed with their previous study on obese mice, where they found a 50\% reduction in the abundance of Bacteroidetes and a proportional increase in Firmicutes [107] and also agreed with major findings of another study of humans in 2006, where they detected a decreased relative proportion of Bacteroidetes in obese individuals [108]. However, a number of studies have failed to confirm these associations and have reported the opposite association [109] or found no association at all [26,110].

Studies have shown that the composition of the diet and the amount of calories consumed are strong modifiers of the microbiota. Zhang et al. (2010) [111] examined genetic susceptibility, diet and weight gain and how they affect the microbiota in Apoa-1 knockout mice compared to wild-type and reported that the majority of the microbiota changes that were detected were associated with the diet [111]. This dietary effect was almost five-times the effect of the genetic susceptibility, reinforcing the traditional view of the dietary impact on weight. However, without a microbiota, germ-free animals are resistant to high-fat diet-induced obesity and metabolic syndrome [112] and genetically identical animals respond differently to a high fat diet [113]. This phenotypic independent association of the microbiota was demonstrated using Sprague-Dawley rats that were found to be obesity-prone or obesity-resistant, depending on their microbiota composition. The obesity-prone rats exhibited increased TLR4 activation, which was associated with ileal inflammation [114], as well as a decrease in intestinal alkaline phosphatase, a luminal enzyme that detoxifies lipopolysaccharide (LPS). This resulted in increased localization of occludin in the cytoplasm of epithelial cells and phosphorylation of the myosin light chain, which is associated with increased intestinal permeability [114]. Furthermore, there were increased concentrations of plasma LPS in the circulatory systems of the rats. It was concluded that the consumption of a high-fat diet induces the changes in the gut microbiota, but the development of inflammation was associated with the appearance of hyperphagia and an obese phenotype. This was 
confirmed in a subsequent study, where it was shown that infusing a low level of LPS for four weeks caused weight gain and insulin resistance without a high-fat diet [115]. Further evidence was provided by Serino et al. (2012) [116], who showed that when genetically identical mice were fed a fat-enriched carbohydrate-free diet, not all mice developed insulin resistance. The subgroup of mice that did show a marked change in insulin sensitivity also presented with a modified gut microbiota. This microbiota (and the increased insulin resistance) was associated with increased gut permeability, increased endotoxaemia and systemic/adipose tissue inflammation. The associated global microbiota changes can be summarised as an inverted Bacteroidetes to Firmicutes ratio with a reduction in the proportional abundance of the Lachnospiracaea family and Oscillibacter genus in the insulin resistant subgroup. Qin et al. (2012) [117] described a decrease in the abundance of butyrate-producing bacteria and an increase in various opportunistic pathogens, as well as an enrichment of other microbial functions conferring sulphate reduction and oxidative stress resistance in diabetic individuals. They did not, however, comment on the association with diet.

The microbiota also affects the expenditure and storage of the nutrients through the expression of genes in the host, such as fasting-induced adipocyte factor (Fiaf). Fiaf is a circulating lipoprotein lipase inhibitor that induces circulating lipoprotein lipase to hydrolyse circulating triacylglycerols to free fatty acids [118]. Bäckhed et al. (2007) [112] investigated obesity associated with a western-style, high fat, high sugar diet in mice and showed that mice responded with increased adiposity, but that animals that were germ-free were protected from obesity. This resistance disappeared in germ-free knockout mice lacking the Fiaf gene and, so, were not protected from the diet-induced obesity. This evidence points to an unfavourable dietary modification of the microbiota being related to the onset of hyperphagia, obesity, insulin resistance and metabolic syndrome.

\section{Conclusion}

Although it has been known for some time that the microbiota performs numerous biological functions that affect the metabolic functions of the host, it is only within the last number of years that the importance of this is becoming apparent. Our intestinal microbial community can affect the rate of deposition and utilization of fat, insulin resistance and diabetes and our inflammation state, as well as our general health and wellbeing. Over recent years, large observational studies and animals trials in combination with high throughput technologies have been used to identify and understand the impact of environmental factors, such as diet and genotype, on controlling the microbiota. The importance of the association of the microbiota and its functions with diet cannot be over-stated in the light of the monumental shifts in diets that have occurred in a very short evolutionarily timeframe. These diets are continuing to change, and it is now estimated that in the United States, a sizeable proportion of individuals consume very little vegetables, with less than half of individuals reporting eating vegetables at dinner. Even less of these individuals include vegetables in lunch foods, like sandwiches and wraps [119]. It may be that our consumption of processed foods, widespread use of antibiotics and disinfectants and our modern lifestyle may have forever altered our ancient gut microbiome. We may never be able to identify or restore our microbiomes to their ancestral state, but dietary modulation to manipulate specific gut microbial species or groups of species may offer new therapeutic approaches to conditions that are prevalent in modern society, such as functional gastrointestinal disorders, obesity 
and maybe even age-related under-nutrition. We predict that this will become an increasingly important area of health research.

\section{Acknowledgments}

Thanks to Eibhlís O'Connor, Simone Rampelli, Hugh Harris and Denise Lynch. This review was supported by the (Government of Ireland) Department of Agriculture Fisheries and Food/Health Research Board FHRI award to the ELDERMET project and a Science Foundation Ireland CSET award to the Alimentary Pharmabiotic Centre.

\section{Conflict of Interest}

The authors declare no conflict of interest.

\section{References}

1. $\quad$ Eckburg, P.B.; Bik, E.M.; Bernstein, C.N.; Purdom, E.; Dethlefsen, L.; Sargent, M.; Gill, S.R.; Nelson, K.E.; Relman, D.A. Diversity of the human intestinal microbial flora. Science 2005, 308, $1635-1638$.

2. Frank, D.N.; St Amand, A.L.; Feldman, R.A.; Boedeker, E.C.; Harpaz, N.; Pace, N.R. Molecular-phylogenetic characterization of microbial community imbalances in human inflammatory bowel diseases. Proc. Natl. Acad. Sci. USA 2007, 104, 13780-13785.

3. Mathis, D.; Benoist, C. Microbiota and autoimmune disease: The hosted self. Cell Host Microbe 2011, 10, 297-301.

4. Hooper, L.V.; Macpherson, A.J. Immune adaptations that maintain homeostasis with the intestinal microbiota. Nat. Rev. Immunol. 2010, 10, 159-169.

5. Hansson, G.C.; Johansson, M.E. The inner of the two Muc2 mucin-dependent mucus layers in colon is devoid of bacteria. Gut Microbes 2010, 1, 51-54.

6. Johansson, M.E.; Phillipson, M.; Petersson, J.; Velcich, A.; Holm, L.; Hansson, G.C. The inner of the two Muc2 mucin-dependent mucus layers in colon is devoid of bacteria. Proc. Natl. Acad. Sci. USA 2008, 105, 15064-15069.

7. Tap, J.; Mondot, S.; Levenez, F.; Pelletier, E.; Caron, C.; Furet, J.-P.; Ugarte, E.; Muñoz-Tamayo, R.; Paslier, D.L.; Nalin, R.; et al. Towards the human intestinal microbiota phylogenetic core. Environ. Microbiol. 2009, 11, 2574-2584.

8. Qin, J.; Li, R.; Raes, J.; Arumugam, M.; Burgdorf, K.S.; Manichanh, C.; Nielsen, T.; Pons, N.; Levenez, F.; Yamada, T.; et al. A human gut microbial gene catalogue established by metagenomic sequencing. Nature 2010, 464, 59-65.

9. Human Microbiome Project Consortium. Structure, function and diversity of the healthy human microbiome. Nature 2012, 486, 207-214.

10. Yatsunenko, T.; Rey, F.E.; Manary, M.J.; Trehan, I.; Dominguez-Bello, M.G.; Contreras, M.; Magris, M.; Hidalgo, G.; Baldassano, R.N.; Anokhin, A.P.; et al. Human gut microbiome viewed across age and geography. Nature 2012, 486, 222-227. 
11. De Filippo, C.; Cavalieri, D.; di Paola, M.; Ramazzotti, M.; Poullet, J.B.; Massart, S.; Collini, S.; Pieraccini, G.; Lionetti, P. Impact of diet in shaping gut microbiota revealed by a comparative study in children from Europe and rural Africa. Proc. Natl. Acad. Sci. USA 2010, 107, 14691-14696.

12. Claesson, M.J.; Jeffery, I.B.; Conde, S.; Power, S.E.; O’Connor, E.M.; Cusack, S.; Harris, H.M.B.; Coakley, M.; Lakshminarayanan, B.; O'Sullivan, O.; et al. Gut microbiota composition correlates with diet and health in the elderly. Nature 2012, 488, 178-184.

13. Wu, G.D.; Chen, J.; Hoffmann, C.; Bittinger, K.; Chen, Y.-Y.; Keilbaugh, S.A.; Bewtra, M.; Knights, D.; Walters, W.A.; Knight, R.; et al. Linking long-term dietary patterns with gut microbial enterotypes. Science 2011, 334, 105-108.

14. Turnbaugh, P.J.; Ley, R.E.; Mahowald, M.A.; Magrini, V.; Mardis, E.R.; Gordon, J.I. An obesity-associated gut microbiome with increased capacity for energy harvest. Nature 2006, 444, 1027-1131.

15. Flint, H.J.; Scott, K.P.; Duncan, S.H.; Louis, P.; Forano, E. Microbial degradation of complex carbohydrates in the gut. Gut Microbes 2012, 3, 289-306.

16. Flint, H.J. The impact of nutrition on the human microbiome. Nutr. Rev. 2012, 70, S10-S13.

17. Leitch, E.C.; Walker, A.W.; Duncan, S.H.; Holtrop, G.; Flint, H.J. Selective colonization of insoluble substrates by human faecal bacteria. Environ. Microbiol. 2007, 9, 667-679.

18. Drescher, L.S.; Thiele, S.; Mensink, G.B. A new index to measure healthy food diversity better reflects a healthy diet than traditional measures. J. Nutr. 2007, 137, 647-651.

19. Guigoz, Y.; Doré, J.; Schiffrin, E.J. The inflammatory status of old age can be nurtured from the intestinal environment. Curr. Opin. Clin. Nutr. Metab. Care 2008, 11, 13-20.

20. Tiihonen, K.; Ouwehand, A.C.; Rautonen, N. Human intestinal microbiota and healthy ageing. Ageing Res. Rev. 2010, 9, 107-116.

21. Ostan, R.; Bucci, L.; Capri, M.; Salvioli, S.; Scurti, M.; Pini, E.; Monti, D.; Franceschi, C. Immunosenescence and immunogenetics of human longevity. Neuroimmunomodulation 2008, 15, 224-240.

22. Biagi, E.; Nylund, L.; Candela, M.; Ostan, R.; Bucci, L.; Pini, E.; Nikkïla, J.; Monti, D.; Satokari, R.; Franceschi, C.; et al. Through ageing, and beyond: Gut microbiota and inflammatory status in seniors and centenarians. PLoS One 2010, 5, e10667.

23. Mäkivuokko, H.; Tiihonen, K.; Tynkkynen, S.; Paulin, L.; Rautonen, N. The effect of age and non-steroidal anti-inflammatory drugs on human intestinal microbiota composition. Br. J. Nutr. 2010, 103, 227-234.

24. Mueller, S.; Saunier, K.; Hanisch, C.; Norin, E.; Alm, L.; Midtvedt, T.; Cresci, A.; Silvi, S.; Orpianesi, C.; Verdenelli, M.C.; et al. Differences in fecal microbiota in different European study populations in relation to age, gender, and country: A cross-sectional study. Appl. Environ. Microbiol. 2006, 72, 1027-1033.

25. Mariat, D.; Firmesse, O.; Levenez, F.; Guimarăes, V.; Sokol, H.; Doré, J.; Corthier, G.; Furet, J.-P. The Firmicutes/Bacteroidetes ratio of the human microbiota changes with age. BMC Microbiol. 2009, 9, doi:10.1186/1471-2180-9-123. 
26. Jumpertz, R.; Le, D.S.; Turnbaugh, P.J.; Trinidad, C.; Bogardus, C.; Gordon, J.I.; Krakoff, J. Energy-balance studies reveal associations between gut microbes, caloric load, and nutrient absorption in humans. Am. J. Clin. Nutr. 2011, 94, 58-65.

27. El Oufir, L.; Flourié, B.; Bruley des Varannes, S.; Barry, J.L.; Cloarec, D.; Bornet, F.; Galmiche, J.P. Relations between transit time, fermentation products, and hydrogen consuming flora in healthy humans. Gut 1996, 38, 870-877.

28. Faust, K.; Sathirapongsasuti, J.F.; Izard, J.; Segata, N.; Gevers, D.; Raes, J.; Huttenhower, C. Microbial co-occurrence relationships in the human microbiome. PLoS Comput. Biol. 2012, 8, e1002606.

29. Flint, H.J.; Duncan, S.H.; Scott, K.P.; Louis, P. Interactions and competition within the microbial community of the human colon: Links between diet and health. Environ. Microbiol. 2007, 9, 1101-1111.

30. Samuel, B.S.; Gordon, J.I. A humanized gnotobiotic mouse model of host-archaeal-bacterial mutualism. Proc. Natl. Acad. Sci. USA 2006, 103, 10011-10016.

31. Jeffery, I.B.; Claesson, M.J.; O’Toole, P.W.; Shanahan, F. Categorization of the gut microbiota: Enterotypes or gradients? Nat. Rev. Microbiol. 2012, 10, 591-592.

32. Louis, P.; Scott, K.P.; Duncan, S.H.; Flint, H.J. Understanding the effects of diet on bacterial metabolism in the large intestine. J. Appl. Microbiol. 2007, 102, 1197-1208.

33. Marks, T.; Farkas, W.R. Effects of a diet deficient in tyrosine and queuine on germfree mice. Biochem. Biophys. Res. Commun. 1997, 230, 233-237.

34. Topping, D.L.; Clifton, P.M. Short-chain fatty acids and human colonic function: Roles of resistant starch and nonstarch polysaccharides. Physiol. Rev. 2001, 81, 1031-1064.

35. Soergel, K.H.; Ruppin, H.; Bar-Meir, S.; Wood, C.M.; Schmitt, M.G., Jr. N-butyrate absorption in the human colon. Dig. Dis. Sci. 1982, 27, 90-92.

36. Donohoe, D.R.; Garge, N.; Zhang, X.; Sun, W.; O’Connell, T.M.; Bunger, M.K.; Bultman, S.J. The microbiome and, butyrate regulate energy metabolism and autophagy in the mammalian colon. Cell Metab. 2011, 13, 517-526.

37. Skutches, C.L.; Sigler, M.H.; Teehan, B.P.; Cooper, J.H.; Reichard, G.A. Contribution of dialysate acetate to energy metabolism: Metabolic implications. Kidney Int. 1983, 23, 57-63.

38. Scheppach, W. Effects of short chain fatty acids on gut morphology and function. Gut 1994, 35, S35-S38.

39. Lewis, S.J.; Heaton, K.W. Increasing, butyrate concentration in the distal colon by accelerating intestinal transit. Gut 1997, 41, 245-251.

40. Gao, Z.; Yin, J.; Zhang, J.; Ward, R.E.; Martin, R.J.; Lefevre, M.; Cefalu, W.T.; Ye, J. Butyrate improves insulin sensitivity and increases energy expenditure in mice. Diabetes 2009, 58, $1509-1517$.

41. Ghosh, S.; Dai, C.; Brown, K.; Rajendiran, E.; Makarenko, S.; Baker, J.; Ma, C.; Halder, S.; Montero, M.; Ionescu, V.A.; et al. Colonic microbiota alters host susceptibility to infectious colitis by modulating inflammation, redox status, and ion transporter gene expression. Am. J. Physiol. Gastrointest. Liver Physiol. 2011, 301, G39-G49. 
42. Zimmer, J.; Lange, B.; Frick, J.-S.; Sauer, H.; Zimmermann, K.; Schwiertz, A.; Rusch, K.; Klosterhalfen, S.; Enck, P. A vegan or vegetarian diet substantially alters the human colonic faecal microbiota. Eur. J. Clin. Nutr. 2012, 66, 53-60.

43. Duncan, S.H.; Louis, P.; Thomson, J.M.; Flint, H.J. The role of $\mathrm{pH}$ in determining the species composition of the human colonic microbiota. Environ. Microbiol. 2009, 11, 2112-2122.

44. Scholz-Ahrens, K.E.; Ade, P.; Marten, B.; Weber, P.; Timm, W.; Açil, Y.; Glüer, C.-C.; Schrezenmeir, J. Prebiotics, probiotics, and synbiotics affect mineral absorption, bone mineral content, and bone structure. J. Nutr. 2007, 137, 838S-846S.

45. Ogawa, H.; Rafiee, P.; Fisher, P.J.; Johnson, N.A.; Otterson, M.F.; Binion, D.G. Butyrate modulates gene and protein expression in human intestinal endothelial cells. Biochem. Biophys. Res. Commun. 2003, 309, 512-519.

46. Whitehead, R.H.; Young, G.P.; Bhathal, P.S. Effects of short chain fatty acids on a new human colon carcinoma cell line (LIM1215). Gut 1986, 27, 1457-1463.

47. Sleeth, M.L.; Thompson, E.L.; Ford, H.E.; Zac-Varghese, S.E.; Frost, G. Free fatty acid receptor 2 and nutrient sensing: A proposed role for fibre, fermentable carbohydrates and short-chain fatty acids in appetite regulation. Nutr. Res. Rev. 2010, 23, 135-145.

48. Hill, M.J. Intestinal flora and endogenous vitamin synthesis. Eur. J. Cancer Prev. 1997, 6, S43-S45.

49. Said, H.M.; Ortiz, A.; McCloud, E.; Dyer, D.; Moyer, M.P.; Rubin, S. Biotin uptake by human colonic epithelial NCM460 cells: A carrier-mediated process shared with pantothenic acid. Am. J. Physiol. 1998, 275, C1365-C1371.

50. Said, H.M.; Ortiz, A.; Subramanian, V.S.; Neufeld, E.J.; Moyer, M.P.; Dudeja, P.K. Mechanism of thiamine uptake by human colonocytes: Studies with cultured colonic epithelial cell line NCM460. Am. J. Physiol. Gastrointest. Liver Physiol. 2001, 281, G144-G150.

51. Said, H.M.; Ortiz, A.; Moyer, M.P.; Yanagawa, N. Riboflavin uptake by human-derived colonic epithelial NCM460 cells. Am. J. Physiol. Cell Physiol. 2000, 278, C270-C276.

52. Said, Z.M.; Subramanian, V.S.; Vaziri, N.D.; Said, H.M. Pyridoxine uptake by colonocytes: A specific and regulated carrier-mediated process. Am. J. Physiol. Cell Physiol. 2008, 294, C1192-C1197.

53. Dudeja, P.K.; Torania, S.A.; Said, H.M. Evidence for the existence of a carrier-mediated folate uptake mechanism in human colonic luminal membranes. Am. J. Physiol. 1997, 272, G1408-G1415.

54. Kim, T.H.; Yang, J.; Darling, P.B.; O’Connor, D.L. A large pool of available folate exists in the large intestine of human infants and piglets. J. Nutr. 2004, 134, 1389-1394.

55. Pompei, A.; Cordisco, L.; Amaretti, A.; Zanoni, S.; Matteuzzi, D.; Rossi, M. Folate production by bifidobacteria as a potential probiotic property. Appl. Environ. Microbiol. 2007, 73, 179-185.

56. Pompei, A.; Cordisco, L.; Amaretti, A.; Zanoni, S.; Raimondi, S.; Matteuzzi, D.; Rossi, M. Administration of folate-producing bifidobacteria enhances folate status in Wistar rats. J. Nutr. 2007, 137, 2742-2746.

57. Strozzi, G.P.; Mogna, L. Quantification of folic acid in human feces after administration of Bifidobacterium probiotic strains. J. Clin. Gastroenterol. 2008, 42, S179-S184. 
58. Leblanc, J.G.; Milani, C.; de Giori, G.S.; Sesma, F.; van Sinderen, D.; Ventura, M. Bacteria as vitamin suppliers to their host: A gut microbiota perspective. Curr. Opin. Biotechnol. 2012, in press.

59. Mathers, J.C.; Fernandez, F.; Hill, M.J.; McCarthy, P.T.; Shearer, M.J.; Oxley, A. Dietary modification of potential vitamin $\mathrm{K}$ supply from enteric bacterial menaquinones in rats. Br. $J$. Nutr. 1990, 63, 639-652.

60. Morishita, T.; Tamura, N.; Makino, T.; Kudo, S. Production of menaquinones by lactic acid bacteria. J. Dairy Sci. 1999, 82, 1897-1903.

61. Ramotar, K.; Conly, J.M.; Chubb, H.; Louie, T.J. Production of menaquinones by intestinal anaerobes. J. Infect. Dis. 1984, 150, 213-218.

62. Duchmann, R.; Kaiser, I.; Hermann, E.; Mayet, W.; Ewe, K.; Meyer zum Büschenfelde, K.H. Tolerance exists towards resident intestinal flora, but is broken in active inflammatory bowel disease (IBD). Clin. Exp. Immunol. 1995, 102, 448-455.

63. Jeffery, I.B.; O’Toole, P.W.; Öhman, L.; Claesson, M.J.; Deane, J.; Quigley, E.M.; Simrén, M. An irritable bowel syndrome subtype defined by species-specific alterations in faecal microbiota. Gut 2012, 61, 997-1006.

64. Isolauri, E. Development of healthy gut microbiota early in life. J. Paediatr. Child. Health 2012, 48, 1-6.

65. Pimentel, M.; Chow, E.J.; Lin, H.C. Eradication of small intestinal bacterial overgrowth reduces symptoms of irritable bowel syndrome. Am. J. Gastroenterol. 2000, 95, 3503-3506.

66. Chang, L. The role of stress on physiological responses and clinical symptoms in irritable bowel syndrome. Gastroenterology 2011, 140, 761-765.

67. Brint, E.K.; MacSharry, J.; Fanning, A.; Shanahan, F.; Quigley, E.M. Differential expression of toll-like receptors in patients with irritable bowel syndrome. Am. J. Gastroenterol. 2011, 106, 329-336.

68. Langhorst, J.; Junge, A.; Rueffer, A.; Wehkamp, J.; Foell, D.; Michalsen, A.; Musial, F.; Dobos, G.J. Elevated human beta-defensin-2 levels indicate an activation of the innate immune system in patients with irritable bowel syndrome. Am. J. Gastroenterol. 2009, 104, 404-410.

69. Pimentel, M.; Lembo, A.; Chey, W.D.; Zakko, S.; Ringel, Y.; Yu, J.; Mareya, S.M.; Shaw, A.L.; Bortey, E.; Forbes, W.P. Rifaximin therapy for patients with irritable bowel syndrome without constipation. N. Engl. J. Med .2011, 364, 22-32.

70. Quigley, E.M. Therapies aimed at the gut microbiota and inflammation: antibiotics, prebiotics, probiotics, synbiotics, anti-inflammatory therapies. Gastroenterol. Clin. North Am. 2011, 40, 207-222.

71. Rajilić-Stojanović, M.; Biagi, E.; Heilig, H.G.; Kajander, K.; Kekkonen, R.A.; Tims, S.; de Vos, W.M. Global and deep molecular analysis of microbiota signatures in fecal samples from patients with irritable bowel syndrome. Gastroenterology 2011, 141, 1792-1801.

72. Salonen, A.; de Vos, W.M.; Palva, A. Gastrointestinal microbiota in irritable bowel syndrome: Present state and perspectives. Microbiology 2010, 156, 3205-3215.

73. Jeffery, I.B.; Quigley, E.M.; Ohman, L.; Simrén, M.; O’Toole, P.W. The microbiota link to irritable bowel syndrome: An emerging story. Gut Microbes 2012, 3, 572-576. 
74. Gibson, P.R.; Shepherd, S.J. Evidence-based dietary management of functional gastrointestinal symptoms: The FODMAP approach. J. Gastroenterol. Hepatol. 2010, 25, 252-258.

75. Gibson, P.R.; Shepherd, S.J. Personal view: Food for thought-Western lifestyle and susceptibility to Crohn's disease. The FODMAP hypothesis. Aliment. Pharmacol. Ther. 2005, 21, 1399-1409.

76. Rumessen, J.J.; Gudmand-Høyer, E. Fructans of chicory: Intestinal transport and fermentation of different chain lengths and relation to fructose and sorbitol malabsorption. Am. J. Clin. Nutr. 1998, 68, 357-364.

77. Gibson, P.R.; Newnham, E.; Barrett, J.S.; Shepherd, S.J.; Muir, J.G. Review article: Fructose malabsorption and the bigger picture. Aliment. Pharmacol. Ther. 2007, 25, 349-363.

78. Itan, Y.; Jones, B.L.; Ingram, C.J.; Swallow, D.M.; Thomas, M.G. A worldwide correlation of lactase persistence phenotype and genotypes. BMC Evol. Biol. 2010, 10, 36.

79. Bate, J.P.; Irving, P.M.; Barrett, J.S.; Gibson, P.R. Benefits of breath hydrogen testing after lactulose administration in analysing carbohydrate malabsorption. Eur. J. Gastroenterol. Hepatol. 2010, 22, 318-326.

80. Rana, S.V.; Sharma, S.; Kaur, J.; Sinha, S.K.; Singh, K. Comparison of lactulose and glucose breath test for diagnosis of small intestinal bacterial overgrowth in patients with irritable bowel syndrome. Digestion 2012, 85, 243-247.

81. Luli, G.W.; Strohl, W.R. Comparison of growth, acetate production, and acetate inhibition of Escherichia coli strains in batch and fed-batch fermentations. Appl. Environ. Microbiol. 1990, 56, 1004-1011.

82. Pimentel, M.; Constantino, T.; Kong, Y.; Bajwa, M.; Rezaei, A.; Park, S. A 14-day elemental diet is highly effective in normalizing the lactulose breath test. Dig. Dis. Sci. 2004, 49, 73-77.

83. Barrett, J.S.; Gearry, R.B.; Muir, J.G.; Irving, P.M.; Rose, R.; Rosella, O.; Haines, M.L.; Shepherd, S.J.; Gibson, P.R. Dietary poorly absorbed, short-chain carbohydrates increase delivery of water and fermentable substrates to the proximal colon. Aliment. Pharmacol. Ther. 2010, 31, 874-882.

84. Mortensen, P.B.; Andersen, J.R.; Arffmann, S.; Krag, E. Short-chain fatty acids and the irritable bowel syndrome: The effect of wheat bran. Scand. J. Gastroenterol. 1987, 22, 185-192.

85. Treem, W.R.; Ahsan, N.; Kastoff, G.; Hyams, J.S. Fecal short-chain fatty acids in patients with diarrhea-predominant irritable bowel syndrome: In vitro studies of carbohydrate fermentation. J. Pediatr. Gastroenterol. Nutr. 1996, 23, 280-286.

86. Malinen, E.; Rinttilä, T.; Kajander, K.; Mättö, J.; Kassinen, A.; Krogius, L.; Saarela, M.; Korpela, R.; Palva, A. Analysis of the fecal microbiota of irritable bowel syndrome patients and healthy controls with real-time PCR. Am. J. Gastroenterol. 2005, 100, 373-382.

87. Louis, P.; Young, P.; Holtrop, G.; Flint, H.J. Diversity of human colonic, butyrate-producing bacteria revealed by analysis of the, butyryl-CoA:acetate CoA-transferase gene. Environ. Microbiol. 2010, 12, 304-314.

88. Bourdu, S.; Dapoigny, M.; Chapuy, E.; Artigue, F.; Vasson, M.-P.; Dechelotte, P.; Bommelaer, G.; Eschalier, A.; Ardid, D. Rectal instillation of, butyrate provides a novel clinically relevant model of noninflammatory colonic hypersensitivity in rats. Gastroenterology 2005, 128, 1996-2008. 
89. Kamath, P.S.; Phillips, S.F.; Zinsmeister, A.R. Short-chain fatty acids stimulate ileal motility in humans. Gastroenterology 1988, 95, 1496-1502.

90. Staudacher, H.M.; Whelan, K.; Irving, P.M.; Lomer, M.C. Comparison of symptom response following advice for a diet low in fermentable carbohydrates (FODMAPs) versus standard dietary advice in patients with irritable bowel syndrome. J. Hum. Nutr. Diet. 2011, 24, 487-495.

91. Monsbakken, K.W.; Vandvik, P.O.; Farup, P.G. Perceived food intolerance in subjects with irritable bowel syndrome-Etiology, prevalence and consequences. Eur. J. Clin. Nutr. 2006, 60, 667-672.

92. El-Salhy, M. Diet and effects of diet management on quality of life and symptoms in patients with irritable bowel syndrome. Mol. Med. Rep. 2012, 5, 1382-1390.

93. Vighi, G.; Marcucci, F.; Sensi, L.; di Cara, G.; Frati, F. Allergy and the gastrointestinal system. Clin. Exp. Immunol. 2008, 153, 3-6.

94. Carroccio, A.; Brusca, I.; Mansueto, P.; Soresi, M.; D’Alcamo, A.; Ambrosiano, G.; Pepe, I.; Iacono, G.; Lospalluti, M.L.; La Chiusa, S.M.; di Fede, G. Fecal assays detect hypersensitivity to cow's milk protein and gluten in adults with irritable bowel syndrome. Clin. Gastroenterol. Hepatol. 2011, 9, 965-971.

95. Guo, H.; Jiang, T.; Wang, J.; Chang, Y.; Guo, H.; Zhang, W. The value of eliminating foods according to food-specific immunoglobulin $\mathrm{G}$ antibodies in irritable bowel syndrome with diarrhoea. J. Int. Med. Res. 2012, 40, 204-210.

96. Biesiekierski, J.R.; Newnham, E.D.; Irving, P.M.; Barrett, J.S.; Haines, M.; Doecke, J.D.; Shepherd, S.J.; Muir, J.G.; Gibson, P.R. Gluten causes gastrointestinal symptoms in subjects without celiac disease: A double-blind randomized placebo-controlled trial. Am. J. Gastroenterol. 2011, 106, 508-514.

97. Frayling, T.M.; Timpson, N.J.; Weedon, M.N.; Zeggini, E.; Freathy, R.M.; Lindgren, C.M.; Perry, J.R.; Elliott, K.S.; Lango, H.; Rayner, N.W.; et al. A common variant in the FTO gene is associated with body mass index and predisposes to childhood and adult obesity. Science 2007, 316, 889-894.

98. Cecil, J.E.; Tavendale, R.; Watt, P.; Hetherington, M.M.; Palmer, C.N. An obesity-associated FTO gene variant and increased energy intake in children. N. Engl. J. Med. 2008, 359, 2558-2566.

99. Chambers, J.C.; Elliott, P.; Zabaneh, D.; Zhang, W.; Li, Y.; Froguel, P.; Balding, D.; Scott, J.; Kooner, J.S. Common genetic variation near MC4R is associated with waist circumference and insulin resistance. Nat. Genet. 2008, 40, 716-718.

100. Loos, R.J.; Lindgren, C.M.; Li, S.; Wheeler, E.; Zhao, J.H.; Prokopenko, I.; Inouye, M.; Freathy, R.M.; Attwood, A.P.; Beckmann, J.S.; et al. Common variants near MC4R are associated with fat mass, weight and risk of obesity. Nat. Genet. 2008, 40, 768-775.

101. Meyre, D.; Delplanque, J.; Chèvre, J.-C.; Lecoeur, C.; Lobbens, S.; Gallina, S.; Durand, E.; Vatin, V.; Degraeve, F.; Proença, C.; et al. Genome-wide association study for early-onset and morbid adult obesity identifies three new risk loci in European populations. Nat. Genet. 2009, 41, 157-159. 
102. Thorleifsson, G.; Walters, G.B.; Gudbjartsson, D.F.; Steinthorsdottir, V.; Sulem, P.; Helgadottir, A.; Styrkarsdottir, U.; Gretarsdottir, S.; Thorlacius, S.; Jonsdottir, I.; et al. Genome-wide association yields new sequence variants at seven loci that associate with measures of obesity. Nat. Genet. 2009, 41, 18-24.

103. Willer, C.J.; Speliotes, E.K.; Loos, R.J.; Li, S.; Lindgren, C.M.; Heid, I.M.; Berndt, S.I.; Elliott, A.L.; Jackson, A.U.; Lamina, C.; et al. Six new loci associated with body mass index highlight a neuronal influence on body weight regulation. Nat. Genet. 2009, 41, 25-34.

104. Tilg, H.; Kaser, A. Gut microbiome, obesity, and metabolic dysfunction. J. Clin. Invest. 2011, 121, 2126-2132.

105. Cani, P.D.; Bibiloni, R.; Knauf, C.; Waget, A.; Neyrinck, A.M.; Delzenne, N.M.; Burcelin, R. Changes in gut microbiota control metabolic endotoxemia-induced inflammation in high-fat diet-induced obesity and diabetes in mice. Diabetes 2008, 57, 1470-1481.

106. Turnbaugh, P.J.; Hamady, M.; Yatsunenko, T.; Cantarel, B.L.; Duncan, A.; Ley, R.E.; Sogin, M.L.; Jones, W.J.; Roe, B.A.; Affourtit, J.P.; et al. A core gut microbiome in obese and lean twins. Nature 2009, 457, 480-484.

107. Ley, R.E.; Bäckhed, F.; Turnbaugh, P.; Lozupone, C.A.; Knight, R.D.; Gordon, J.I. Obesity alters gut microbial ecology. Proc. Natl. Acad. Sci. USA 2005, 102, 11070-11075.

108. Ley, R.E.; Turnbaugh, P.J.; Klein, S.; Gordon, J.I. Microbial ecology: Human gut microbes associated with obesity. Nature 2006, 444, 1022-1023.

109. Schwiertz, A.; Taras, D.; Schäfer, K.; Beijer, S.; Bos, N.A.; Donus, C.; Hardt, P.D. Microbiota and SCFA in lean and overweight healthy subjects. Obesity (Silver Spring) 2010, 18, 190-195.

110. Duncan, S.H.; Lobley, G.E.; Holtrop, G.; Ince, J.; Johnstone, A.M.; Louis, P.; Flint, H.J. Human colonic microbiota associated with diet, obesity and weight loss. Int. J. Obes. (Lond.) 2008, 32, $1720-1724$.

111. Zhang, C.; Zhang, M.; Wang, S.; Han, R.; Cao, Y.; Hua, W.; Mao, Y.; Zhang, X.; Pang, X.; Wei, C.; et al. Interactions between gut microbiota, host genetics and diet relevant to development of metabolic syndromes in mice. ISME J. 2010, 4, 232-241.

112. Bäckhed, F.; Manchester, J.K.; Semenkovich, C.F.; Gordon, J.I. Mechanisms underlying the resistance to diet-induced obesity in germ-free mice. Proc. Natl. Acad. Sci. USA 2007, 104, 979-984.

113. De La Serre, C.B.; Ellis, C.L.; Lee, J.; Hartman, A.L.; Rutledge, J.C.; Raybould, H.E. Propensity to high-fat diet-induced obesity in rats is associated with changes in the gut microbiota and gut inflammation. Am. J. Physiol. Gastrointest. Liver Physiol. 2010, 299, G440-G448.

114. Shen, L.; Black, E.D.; Witkowski, E.D.; Lencer, W.I.; Guerriero, V.; Schneeberger, E.E.; Turner, J.R. Myosin light chain phosphorylation regulates barrier function by remodeling tight junction structure. J. Cell Sci. 2006, 119, 2095-2106.

115. Cani, P.D.; Amar, J.; Iglesias, M.A.; Poggi, M.; Knauf, C.; Bastelica, D.; Neyrinck, A.M.; Fava, F.; Tuohy, K.M.; Chabo, C.; et al. Metabolic endotoxemia initiates obesity and insulin resistance. Diabetes 2007, 56, 1761-1772.

116. Serino, M.; Luche, E.; Gres, S.; Baylac, A.; Bergé, M.; Cenac, C.; Waget, A.; Klopp, P.; Iacovoni, J.; Klopp, C.; et al. Metabolic adaptation to a high-fat diet is associated with a change in the gut microbiota. Gut 2012, 61, 543-553. 
117. Qin, J.; Li, Y.; Cai, Z.; Li, S.; Zhu, J.; Zhang, F.; Liang, S.; Zhang, W.; Guan, Y.; Shen, D.; et al. A metagenome-wide association study of gut microbiota in type 2 diabetes. Nature 2012, 490, 55-60.

118. Bäckhed, F.; Ding, H.; Wang, T.; Hooper, L.V.; Koh, G.Y.; Nagy, A.; Semenkovich, C.F.; Gordon, J.I. The gut microbiota as an environmental factor that regulates fat storage. Proc. Natl. Acad. Sci. USA 2004, 101, 15718-15723.

119. Satia, J.A.; Kristal, A.R.; Patterson, R.E.; Neuhouser, M.L.; Trudeau, E. Psychosocial factors and dietary habits associated with vegetable consumption. Nutrition 2002, 18, 247-254.

(C) 2013 by the authors; licensee MDPI, Basel, Switzerland. This article is an open access article distributed under the terms and conditions of the Creative Commons Attribution license (http://creativecommons.org/licenses/by/3.0/). 